\title{
Replicated Association Study for Metabolic Syndrome of the Gene Cluster in Chromosome 11q23.3
}

\author{
Sung-Soo Kim* ${ }^{*}$, Sangjung Park ${ }^{\dagger, * *}$ and Hyun-Seok Jin ${ }^{\dagger, * *}$ \\ Department of Biomedical Laboratory Science, College of Life and Health Sciences, \\ Hoseo University, Asan, Chungnam 31499, Korea
}

\begin{abstract}
Metabolic syndrome (MetS) is a disease that is accompanied by various metabolic related problems and refers to a disease in which various adult diseases occur along with obesity. These metabolic syndromes appear according to the individual's genetic background. APOA5-ZPR1-BUD13, a gene cluster belonging to chromosome 11q23.3, is well known for its risk of plasma triglycerides and coronary artery disease. Recently, the GWAS results for metabolic syndrome were published in Koreans. The results included the APOA5-ZPR1-BUD13, and the SNPs that first appeared in Koreans in the ZPR1 and $B U D 13$ were also discovered. In this study, the reproducibility was investigated for the newly discovered ZPR1 (rs964184) and BUD13 (rs2075295, rs1558861) using The Health Examinees (HEXA) cohort and showed significance. In addition, BUD13 (rs117548857, rs10488698, rs149527022, rs10790162), ZPR1 (rs2075290, rs145796806, rs201247587), APOA5 (rs12791103, rs1263173, rs7396835, rs17520254) were additionally discovered and significant results were obtained. For the SNPs that showed significant results, the effect on protein expression and the effect of expression quantitative trait loci (eQTL) were also confirmed. This study is expected to contribute to the prevention and treatment of diseases with differences in onset based on individual genetic patterns as well as presenting the effect of genetic mutations in the APOA5-ZPR1-BUD13 on metabolic syndrome and blood lipid levels.
\end{abstract}

Key Words: Metabolic syndrome (MetS), APOA5, ZPR1, BUD13, SNP

\section{서 론}

대사증후군(metabolic syndrome; MetS)은 여러 가지 신 진대사와 관련된 문제가 동반되는 질환으로 고중성지방 혈증, 낮은 고밀도콜레스테롤, 고혈압 및 당뇨병을 비롯 한 각종 성인병이 복부 비만과 함께 발생하는 질환이다 (Eckel et al., 2005). 전세계적으로 대사증후군 유병률은 계
속해서 증가하는 추세이며 국내에서는 약 $30 \%$ 의 유병률 을 보이고 있다(Wang et al., 2007; Aguilar et al., 2015; Lee et al., 2018). 이러한 대사증후군은 발병 후 방치하게 되면 뇌졸중과 협심증을 비롯한 심혈관질환의 위험성이 크게 증가한다(Mottillo et al., 2010; Lee et al., 2019). 따라서 대사증 후군의 예방과 치료의 중요성이 높아지고 있다. 대사증후 군의 발병에는 개인의 유전적 요소가 영향을 준다(Sung et al., 2009). 따라서 대사증후군의 발병과 관련된 위험 요인

Received: December 8, 2020 / Revised: December 15, 2020 / Accepted: December 15, 2020

* Graduate student, ${ }^{* *}$ Professor.

${ }^{\dagger}$ Corresponding author: Hyun-Seok Jin. Department of Biomedical Laboratory Science, College of Life and Health Sciences, Hoseo University, 20 Hoseo-ro 79 Beon-gil, Asan-si, Chungnam 31499, Korea.

Tel: +82-41-540-9968, Fax: +82-41-540-9997, e-mail: jinhs@hoseo.edu

${ }^{\dagger}$ Corresponding author: Sangjung Park. Department of Biomedical Laboratory Science, College of Life and Health Sciences, Hoseo University, 20 Hoseo-ro 79 Beon-gil, Asan-si, Chungnam 31499, Korea.

Tel: +82-41-540-9967, Fax:+82-41-540-9997, e-mail: sangjung@hoseo.edu

(C) The Korean Society for Biomedical Laboratory Sciences. All rights reserved.

(c) This is an Open Access article distributed under the terms of the Creative Commons Attribution Non-Commercial License (http:/creativecommons.org/licenses/by-nc/3.0/) which permits unrestricted non-commercial use, distribution, and reproduction in any medium, provided the original work is properly cited. 
Table 1. Basic characteristics of subjects according to metabolic syndrome in HEXA

\begin{tabular}{lccc}
\hline \hline \multicolumn{1}{c}{ Characteristics } & Total & MetS $^{*}$ & Controls $^{* *}$ \\
\hline Number of subjects & 28,445 & 6,329 & 11,773 \\
Age (M years \pm SD) & $53.84 \pm 7.98$ & $56.56 \pm 7.61$ & $50.95 \pm 7.53$ \\
Sex [male (\%)] & $10,261(36.1 \%)$ & $2,861(45.2 \%)$ & $3,849(32.7 \%)$ \\
WC (M cm \pm SD) & $80.86 \pm 8.65$ & $87.93 \pm 7.74$ & $78.01 \pm 7.76$ \\
TG (M mg/dL \pm SD) & $126.44 \pm 86.63$ & $197.75 \pm 117.77$ & $102.91 \pm 61.22$ \\
HDL-C (M mg/dL \pm SD) & $52.77 \pm 12.66$ & $44.18 \pm 9.53$ & $55.83 \pm 12.42$ \\
GLU (M mg/dL \pm SD) & $94.39 \pm 19.52$ & $106.61 \pm 27.37$ & $88.83 \pm 10.56$ \\
SBP (M mmHg \pm SD) & $122.39 \pm 14.65$ & $130.93 \pm 13.98$ & $118.06 \pm 13.50$ \\
DBP (M mmHg \pm SD) & $75.99 \pm 9.66$ & $80.46 \pm 9.36$ & $73.50 \pm 9.31$ \\
\hline
\end{tabular}

Abbreviations: DBP, diastolic blood pressure; GLU, fasting glucose; HDL-C, high density lipoprotein cholesterol; HEXA, The Health Examinees; M, mean; MetS, metabolic syndrome; SBP, systolic blood pressure; SD, standard deviation; TG, triglyceride; WC, waist circumference. ${ }^{*}$ MetS have 3 or more of 5 indicators that can be diagnosed as metabolic syndrome. ${ }^{* *}$ The controls are the group without metabolic syndrome and various diseases and diseases

으로 작용하는 기전과 유전자의 규명에 대한 중요성이 부 각되고 있다(Kim et al., 2011; Kraja et al., 2011).

이전 연구에서는 염색체 $11 \mathrm{q} 23.3$ 의 속한 유전자 클러스 터(SIK3-BUD13-ZPR1-APOA5-APOA4)가 혈장 중성지방과 관상 동맥질환의 위험성과 관련이 있음을 보고한 바 있 다(Fu et al., 2015; Kim et al., 2019). 최근 Oh 등은 한국인을 대상으로 대사증후군에 대한 genome-wide association study (GWAS)를 수행하여 다양한 유전자에서 유의성이 나타난 $\mathrm{SNP}$ 을 발표하였다(Oh et al., 2020). 발표된 유전자들 중에 는 11q23.3 유전자 클러스터인 BUD13-ZPR1-APOA5 유 전자도 포함되어 있었으며 $B U D 13, Z P R 1$ 유전자는 한국 인에서 처음 나타난 $\mathrm{SNP}$ 도 발굴되었다. 따라서 이번 연 구에서는 앞선 연구와는 다른 코호트 자료를 활용하여 BUD13-ZPR1-APOA5를 대상으로 유전적 변이가 대사증 후군 발병에 미치는 영향을 확인해보고자 하였다. 또한, 중성지방과 관련하여 한국인에서 처음 나타난 $B U D 13$ 의 rs2075295, rs1558861과 ZPRI의 rs964184가 이번 연구에서 $\mathrm{MetS}$ 와 연관성이 있는지 알아보았다.

\section{대상 및 방법}

\section{연구대상자}

연구대상자는 한국인 유전체 역학 조사 사업(Korean Genome and Epidemiology Study; KoGES)의 일환인 HEXA (The Health Examinees) 코호트 자료를 분양 받아 활용하 였다(Health Examinees Study Group, 2015) (KBN-2017-046).
HEXA 코호트 자료는 40세 이상의 남녀를 모집하였으며 일부인 28,445(남성: 10,261 명, 여성: 18,184 명)명의 유전형 을 분석하였다. 28,455 명은 이번 연구의 분석대상자로 적 합하였으며 Table 1과 같다. 대사증후군 환자군은 국내에 서 사용하는 대사증후군 진단 기준인 National Cholesterol Education Program (NCEP) Adult Treatment Panel III 지침에 서 복부 비만을 한국인의 기준에 맞게 사용하였다(Expert Panel on Detection, Evaluation, and Treatment of High Blood Cholesterol in Adults, 2001; Oh and Kim, 2016). 따라서 허리 둘레(남자 $90 \mathrm{~cm}$, 여자 $85 \mathrm{~cm}$ 이상), 중성지방 $150 \mathrm{mg} / \mathrm{dL}$ 이상 또는 관련 약물 복용), HDL cholesterol (남자 $40 \mathrm{mg}$ / $\mathrm{dL}$, 여자 $50 \mathrm{mg} / \mathrm{dL}$ 이하), 수축기 혈압 $130 \mathrm{mmHg}$ 또는 이 완기 혈압 $85 \mathrm{mmHg}$ 이상 또는 혈압약 복용자, 공복혈당 $(100 \mathrm{mg} / \mathrm{dL}$ 이상 또는 당뇨병 과거력 또는 당뇨 관련 약 물 복용)이라는 총 5 종류의 지표들 중에 3 가지 이상에 해 당하면 대사증후군 환자로 분류하여 6,329 명을 선별하였 다. 건강 대조군으로는 대사증후군을 포함한 고혈압, 당뇨 병, 고지혈증, 뇌졸중, 협심증, 급성 간 질환, 지방간, 관절 염, 골다공증, 통풍을 진단받은 과거력이 없는 11,773 명 을 선별하였다. 이번 연구에 활용한 유전정보는 질병관 리본부(KNIH)와 호서대학교에서 연구윤리 승인(IRB No.: 1041231-170822-BR-062-01)을 받아 수행하였다.

\section{유전형 분석과 SNP 선별}

유전형 분석은 K-CHIP consortium에서 제공하는 Affymetrix Axiom ${ }^{\mathrm{TM}}$ KORV1.0-96 Array (Affymetrix, Santa Clara, 
Table 2. Association results for metabolic syndrome targeting SNPs of three genes BUD13, ZPR1 and APOA5 located on chromosome 11

\begin{tabular}{|c|c|c|c|c|c|c|c|c|c|c|}
\hline \multirow[b]{2}{*}{ Gene } & \multirow[b]{2}{*}{ No. } & \multirow[b]{2}{*}{ SNP } & \multirow[b]{2}{*}{$\mathrm{BP}$} & \multirow[b]{2}{*}{ Function } & \multirow[b]{2}{*}{$\mathrm{A} 1$} & \multirow[b]{2}{*}{ A2 } & \multicolumn{2}{|c|}{ MAF } & \multirow[b]{2}{*}{ OR $(95 \% \mathrm{CI})$} & \multirow[b]{2}{*}{${ }^{*} P$ value } \\
\hline & & & & & & & $\begin{array}{c}\text { Cases } \\
(\mathrm{n}=6,329)\end{array}$ & $\begin{array}{c}\text { Control } \\
(\mathrm{n}=11,773)\end{array}$ & & \\
\hline \multirow{7}{*}{ BUD13 } & 1 & rs 117548857 & 116604167 & 3' UTR near & $\mathrm{G}$ & $\mathrm{T}$ & 0.016 & 0.020 & $0.80(0.67 \sim 0.96)$ & 0.015 \\
\hline & 2 & rs1558861 & 116607437 & 3' UTR near & $\mathrm{C}$ & $\mathrm{T}$ & 0.251 & 0.213 & $1.27(1.20 \sim 1.34)$ & $8.63 \times 10^{-18}$ \\
\hline & 3 & rs11216126 & 116617240 & 3' UTR near & $\mathrm{C}$ & A & 0.175 & 0.202 & $0.83(0.78 \sim 0.88)$ & $9.44 \times 10^{-10}$ \\
\hline & 4 & rs2075295 & 116628401 & Intron & $\mathrm{C}$ & $\mathrm{T}$ & 0.430 & 0.470 & $0.84(0.80 \sim 0.88)$ & $1.87 \times 10^{-13}$ \\
\hline & 5 & rs10488698 & 116633947 & Missense & A & G & 0.062 & 0.067 & $0.90(0.82 \sim 0.99)$ & 0.029 \\
\hline & 6 & rs149527022 & 116635570 & Intron & G & A & 0.009 & 0.013 & $0.69(0.55 \sim 0.87)$ & $1.62 \times 10^{-3}$ \\
\hline & 7 & rs10790162 & 116639104 & Intron & A & G & 0.244 & 0.206 & $1.27(1.20 \sim 1.34)$ & $9.41 \times 10^{-18}$ \\
\hline \multirow{5}{*}{ ZPRI } & 8 & rs964184 & 116648917 & 3' UTR & G & $\mathrm{C}$ & 0.247 & 0.209 & $1.27(1.21 \sim 1.35)$ & $3.66 \times 10^{-18}$ \\
\hline & 9 & rs145796806 & 116650184 & Intron & $\mathrm{T}$ & $\mathrm{C}$ & 0.012 & 0.013 & $0.94(0.76 \sim 1.16)$ & 0.575 \\
\hline & 10 & rs2075290 & 116653296 & Intron & $\mathrm{C}$ & $\mathrm{T}$ & 0.250 & 0.213 & $1.26(1.19 \sim 1.33)$ & $9.36 \times 10^{-17}$ \\
\hline & 11 & rs603446 & 116654435 & Intron & $\mathrm{T}$ & $\mathrm{C}$ & 0.208 & 0.232 & $0.86(0.82 \sim 0.91)$ & $2.05 \times 10^{-7}$ \\
\hline & 12 & rs201247587 & 116658553 & Missense & G & $\mathrm{T}$ & 0.013 & 0.013 & $1.05(0.85 \sim 1.30)$ & 0.642 \\
\hline \multirow{8}{*}{$A P O A 5$} & 13 & rs2266788 & 116660686 & 3' UTR & $\mathrm{G}$ & $\mathrm{A}$ & 0.248 & 0.210 & $1.27(1.21 \sim 1.34)$ & $4.59 \times 10^{-18}$ \\
\hline & 14 & rs2075291 & 116661392 & Missense & A & $\mathrm{C}$ & 0.100 & 0.074 & $1.41(1.30 \sim 1.53)$ & $5.84 \times 10^{-17}$ \\
\hline & 15 & rs662799 & 116663707 & 5' UTR & G & A & 0.349 & 0.285 & $1.38(1.32 \sim 1.45)$ & $1.45 \times 10^{-37}$ \\
\hline & 16 & rs17520254 & 116665553 & 5' UTR near & G & $\mathrm{C}$ & 0.015 & 0.018 & $0.83(0.69 \sim 1.00)$ & 0.054 \\
\hline & 17 & rs117730008 & 116666341 & 5' UTR near & A & G & 0.052 & 0.053 & $0.99(0.89 \sim 1.10)$ & 0.834 \\
\hline & 18 & rs12791103 & 116673315 & 5' UTR near & $\mathrm{T}$ & G & 0.036 & 0.043 & $0.82(0.72 \sim 0.92)$ & $8.94 \times 10^{-4}$ \\
\hline & 19 & rs1263173 & 116681008 & 5' UTR near & A & G & 0.272 & 0.286 & $0.94(0.89 \sim 0.98)$ & 0.011 \\
\hline & 20 & rs7396835 & 116684028 & 5' UTR near & $\mathrm{T}$ & $\mathrm{C}$ & 0.336 & 0.311 & $1.13(1.08 \sim 1.19)$ & $1.14 \times 10^{-6}$ \\
\hline
\end{tabular}

Abbreviations: 3' UTR, three prime untranslated region; 5' UTR, five prime untranslated region; A1, minor allele; A2, major allele; $\mathrm{BP}$, base pair; CI, confidence interval; MAF, minor allele frequency; No, number; OR, odds ratio; SNP, single nucleotide polymorphism. $* P$ value $<0.05$ are indicated in bold. The genetic model of the analysis was performed with an additive model and covariates with sex and age

$\mathrm{CA}, \mathrm{USA}$ )인 Korean Chip (K-CHIP)을 사용하여 유전형을 확인한 결과를 사용하였다(Moon et al., 2019). 그 과정에서 DNA 시료는 연구 참여자의 말초혈액에서 분리 추출하 였고, 유전형 판독 정확도가 96 99\% 이하이거나, 과도한 heterozygosity를 가지거나, 성별 불일치가 존재하는 대상 자들은 제외하였다. 본 연구에서는 $B U D 13, Z P R 1, A P O A 5$ 유전자와 인근의 $\mathrm{SNP}$ 들을 대상으로 분석하였다. 염색 체 상의 위치는 UCSC (University of Colombo school of computing) Genome browser on human Feb, 2009 (Genome Reference Consortium Human Build 37)를 기준으로 하였다.

\section{통계 분석}

대부분의 통계 분석에는 PLINK version 1.90 beta (http:// pngu.mgh.harvard.edu/ purcell/plink)와 PASW Statistics version 21.0 (SPSS Inc. Chicago, IL, USA)을 사용하였다. 대사증
후군 환자군과 건강 대조군에 대한 유전 변이의 상관 분 석은 로지스틱 회귀 분석을 사용하였고 대사증후군과 관 련된 표현형에 대한 분석은 선형회귀 분석을 사용하였 다. 또한, 선형회귀 분석에서는 정확한 분석을 위해 약물 복용과 같은 치료를 받는 경우 제외하였다. 유전 모형은 additive model을 기준으로 하였다. 회귀 분석의 시행에 있 어서 나이와 성별을 공변수로 조정하여 분석하였고 분석 값에 대한 유의성의 기준은 0.05 미만을 기준으로 하였 다. 분석한 유전 정보를 바탕으로 Haploview version 4.2 (Whitehead Institute for Biomedical Research, Cambridge, MA, USA) 프로그램을 사용하여 연관불균형(linkage disequilibrium)을 확인하였다. 


\section{결 과}

\section{대사증후군에 대한 로지스틱 회귀분석 결과}

세 유전자에 대한 총 20 개의 $\mathrm{SNP}$ 이 대사증후군 발병 에 미치는 영향은 Table 2 와 같다. BUD13 유전자 인근의 영역까지 포함하여 7개의 $\mathrm{SNP}$ 이 존재하였으며 모두 대 사증후군과 유의한 결과를 나타냈다 $(P<0.05) . Z P R 1$ 유전 자 영역에는 5 개의 $\mathrm{SNP}$ 이 포함되었으며 3 개의 $\mathrm{SNP}$ (rs964184, rs2075290, rs603446)이 유의성을 보였다. APOA5 유 전자 인근의 영역까지 포함해 8 개의 $\mathrm{SNP}$ 이 존재하였으 며 6개의 SNP (rs2266788, rs2075291, rs662799, rs12791103, rs1263173, rs7396835)이 유의한 결과를 보였다. 가장 높 은 유의성 $\left(P=1.45 \times 10^{-37}\right)$ 을 보이는 $A P O A 5$ 의 rs662799는 minor allele인 $\mathrm{G}$ 염기를 보유할 경우 대사증후군에 상대 적 위험도(OR)가 1.38 (95\% CI: 1.32 1.45)로 증가하는 것
으로 나타났다. Oh 등의 연구에서는 $\mathrm{TG}$ 와 관련하여 한국 인에게 처음으로 발견된 $B U D 13$ 의 rs1558861, rs2075295 과 ZPRI의 $\mathrm{r} 964184$ 는 상대적 위험도 $(95 \% \mathrm{Cl}$ )가 각 1.27 (1.20 1.34), 0.84 (0.80 0.88), 1.27 (1.21 1.35)로 나타났고 이번 연구에서도 유의한 결과를 나타냈다(Oh et al., 2020). $B U D 13$ 의 rs117548857, rs10488698, rs149527022, rs10790162 와 ZPRI의 rs2075290과 $A P O A 5$ 의 rs12791103, rs1263173, rs7396835는 한국인을 대상으로 한 이번 연구를 통해 대 사증후군과 관련하여 처음으로 발굴된 $\mathrm{SNP}$ 이다.

\section{$B U D 13, Z P R 1, A P O A 5 \mathrm{SNP}$ 들의 선형회귀 분석 결과}

총 20 개의 SNP에 대하여 대사증후군을 진단하는 지표 인 허리둘레(waist circumference; WC), 중성지방(triglyceride; $\mathrm{TG})$, 고비중지단백-콜레스테롤(high density lipoprotein cholesterol; HDL-C), 공복혈당(fasting glucose; GLU), 수축기 혈 압(systolic blood pressure; SBP), 이완기 혈압(diastolic blood

Table 3. Association results of metabolic syndrome related indicators in SNPs of three genes $B U D 13, Z P R 1$ and $A P O A 5$

\begin{tabular}{|c|c|c|c|c|c|c|c|c|c|}
\hline \multirow{2}{*}{ Gene } & \multirow{2}{*}{ No. } & \multirow{2}{*}{ SNP } & \multirow{2}{*}{$\mathrm{A} 1$} & \multicolumn{2}{|c|}{ TG } & \multicolumn{2}{|c|}{ HDL-C } & \multicolumn{2}{|c|}{ GLU } \\
\hline & & & & $\beta \pm \mathrm{s.e}$ & $P$ value & $\beta \pm$ s.e & $P$ value & $\beta \pm$ s.e & $P$ value \\
\hline \multirow{7}{*}{$B U D 13$} & 1 & rs 117548857 & $\mathrm{G}$ & $-12.78 \pm 2.60$ & $8.68 \times 10^{-7}$ & $0.71 \pm 0.38$ & 0.061 & $0.66 \pm 0.47$ & 0.163 \\
\hline & 2 & rs 1558861 & $\mathrm{C}$ & $16.42 \pm 0.86$ & $4.96 \times 10^{-81}$ & $-1.57 \pm 0.13$ & $1.04 \times 10^{-35}$ & $0.21 \pm 0.16$ & 0.174 \\
\hline & 3 & rs11216126 & $\mathrm{C}$ & $-13.90 \pm 0.91$ & $1.39 \times 10^{-52}$ & $1.75 \pm 0.13$ & $9.63 \times 10^{-40}$ & $-0.53 \pm 0.16$ & 0.001 \\
\hline & 4 & rs2075295 & $\mathrm{C}$ & $-12.39 \pm 0.72$ & $4.68 \times 10^{-66}$ & $1.59 \pm 0.11$ & $1.48 \times 10^{-51}$ & $-0.30 \pm 0.13$ & 0.024 \\
\hline & 5 & rs10488698 & A & $-8.92 \pm 1.43$ & $4.42 \times 10^{-10}$ & $1.52 \pm 0.21$ & $3.47 \times 10^{-13}$ & $0.40 \pm 0.26$ & 0.120 \\
\hline & 6 & rs149527022 & G & $-5.98 \pm 3.30$ & 0.070 & $0.45 \pm 0.48$ & 0.353 & $-0.08 \pm 0.60$ & 0.892 \\
\hline & 7 & rs10790162 & A & $16.83 \pm 0.87$ & $6.70 \times 10^{-83}$ & $-1.66 \pm 0.13$ & $9.64 \times 10^{-39}$ & $0.27 \pm 0.16$ & 0.086 \\
\hline \multirow{5}{*}{ ZPRI } & 8 & rs964184 & G & $16.75 \pm 0.87$ & $1.07 \times 10^{-82}$ & $-1.67 \pm 0.13$ & $2.26 \times 10^{-39}$ & $0.23 \pm 0.16$ & 0.148 \\
\hline & 9 & rs145796806 & $\mathrm{T}$ & $-14.68 \pm 3.21$ & $4.76 \times 10^{-6}$ & $1.44 \pm 0.47$ & 0.002 & $-0.60 \pm 0.57$ & 0.295 \\
\hline & 10 & rs 2075290 & $\mathrm{C}$ & $16.52 \pm 0.86$ & $1.13 \times 10^{-81}$ & $-1.64 \pm 0.13$ & $7.79 \times 10^{-39}$ & $0.18 \pm 0.16$ & 0.252 \\
\hline & 11 & rs603446 & $\mathrm{T}$ & $-12.29 \pm 0.86$ & $1.36 \times 10^{-46}$ & $0.96 \pm 0.13$ & $2.16 \times 10^{-44}$ & $0.00 \pm 0.15$ & 0.990 \\
\hline & 12 & rs201247587 & $\mathrm{G}$ & $12.41 \pm 3.28$ & $1.55 \times 10^{-4}$ & $-2.22 \pm 0.48$ & $3.53 \times 10^{-6}$ & $-0.41 \pm 0.59$ & 0.483 \\
\hline \multirow{8}{*}{ APOA5 } & 13 & rs 2266788 & G & $16.91 \pm 0.86$ & $1.63 \times 10^{-84}$ & $-1.67 \pm 0.13$ & $1.61 \times 10^{-39}$ & $0.21 \pm 0.16$ & 0.191 \\
\hline & 14 & rs 2075291 & A & $33.66 \pm 1.32$ & $1.21 \times 10^{-141}$ & $-4.08 \pm 0.19$ & $4.17 \times 10^{-98}$ & $0.48 \pm 0.24$ & 0.046 \\
\hline & 15 & rs662799 & G & $25.35 \pm 0.77$ & $9.50 \times 10^{-234}$ & $-2.76 \pm 0.11$ & $4.59 \times 10^{-130}$ & $0.31 \pm 0.14$ & 0.030 \\
\hline & 16 & rs17520254 & G & $-7.63 \pm 2.74$ & 0.005 & $1.62 \pm 0.40$ & $4.81 \times 10^{-5}$ & $0.15 \pm 0.49$ & 0.763 \\
\hline & 17 & rs117730008 & A & $-2.19 \pm 1.63$ & 0.179 & $0.18 \pm 0.24$ & 0.444 & $-0.45 \pm 0.29$ & 0.127 \\
\hline & 18 & rs12791103 & $\mathrm{T}$ & $-10.72 \pm 1.79$ & $2.33 \times 10^{-9}$ & $1.73 \pm 0.26$ & $3.49 \times 10^{-11}$ & $-0.03 \pm 0.32$ & 0.938 \\
\hline & 19 & rs1263173 & A & $-2.47 \pm 0.81$ & 0.002 & $0.15 \pm 0.12$ & 0.216 & $-0.47 \pm 0.15$ & 0.001 \\
\hline & 20 & rs7396835 & $\mathrm{T}$ & $8.80 \pm 0.77$ & $6.42 \times 10^{-30}$ & $-0.55 \pm 0.11$ & $1.22 \times 10^{-6}$ & $0.25 \pm 0.14$ & 0.069 \\
\hline
\end{tabular}

Abbreviations: $\beta$, regression coefficient; $\mathrm{Al}$, minor allele; GLU, fasting glucose; HDL-C, high density lipoprotein cholesterol; s.e, standard error; SNP, single nucleotide polymorphism; TG, triglyceride. $P$ value $<0.05$ are indicated in bold. The genetic model of the analysis was performed with an additive model and covariates with sex and age. Systolic blood pressure and diastolic blood pressure were not significant 


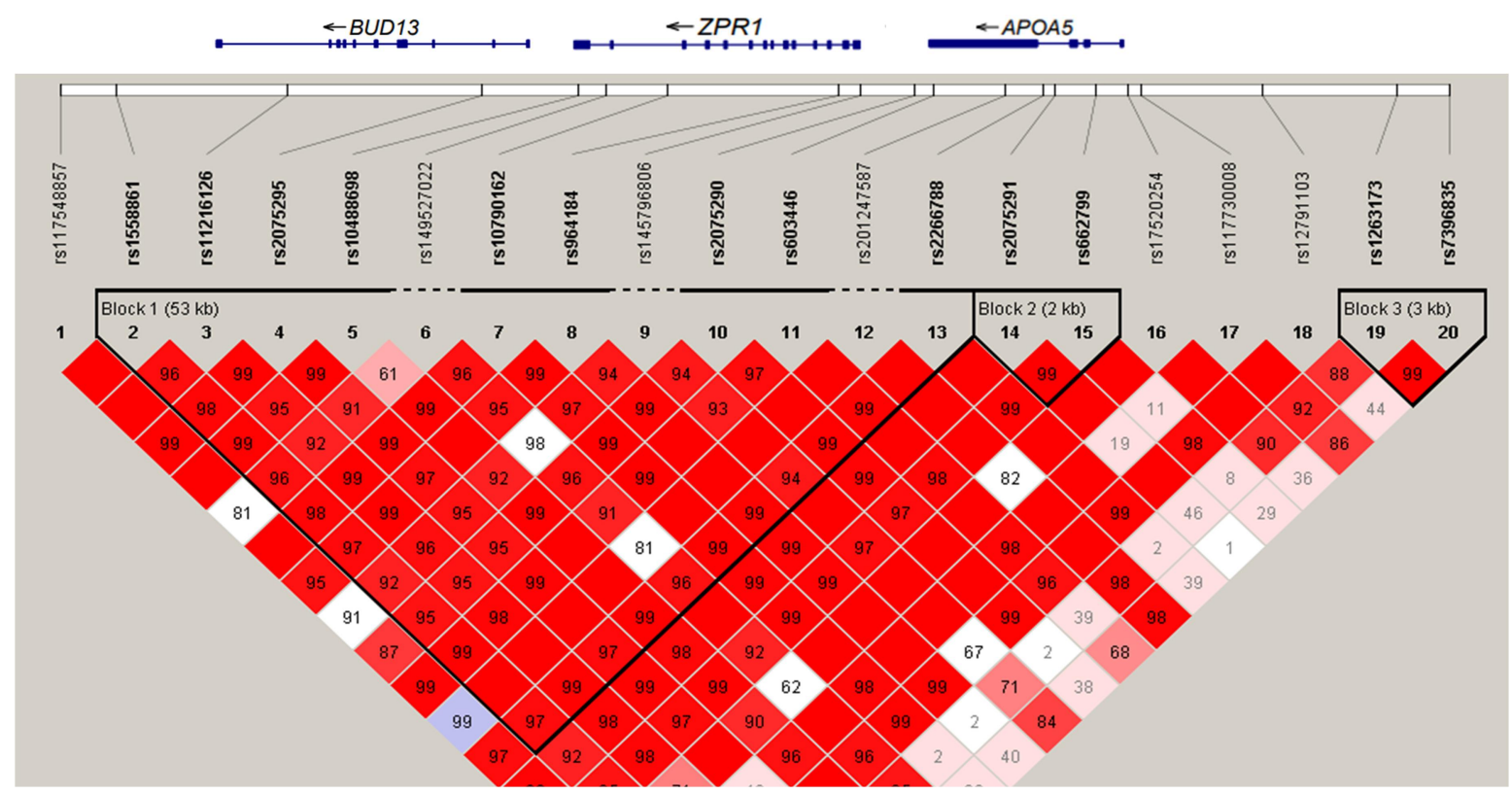

Fig. 1. Linkage disequilibrium results between three genes $B U D 13, Z P R 1$ and $A P O A 5$ belonging to the gene cluster of $11 \mathrm{q} 23.3$. Linkage disequilibrium (LD) blocks were formed between SNPs using Haploview program based on HEXA data. A total of 3 blocks were formed, and Block 1 contained the SNPs of BUD13 and ZPR1. Among them, 3 SNPs showing a low minor allele frequency were excluded. Block 2 contained the SNP of the APOA5, and the direction to the metabolic syndrome was consistent. Block 3 included SNPs near the APOA5.

pressure; DBP)에 미치는 영향을 확인하였고 유의성을 나 타낸 TG, HDL-C, GLU의 관한 결과는 Table 3과 같다. 대 사증후군에 관해 가장 유의한 결과를 나타낸 rs662799는 선형회귀 분석 결과 minor allele를 가질 때 $\mathrm{TG}$ 의 기울기 가 증가하였고 $\mathrm{HDL}-\mathrm{C}$ 의 기울기 감소, GLU의 기울기 증 가로 대사증후군 발병 위험과 관련된 결과를 나타냈다. 이러한 결과는 MetS의 상대적 위험도가 높게 나타난 결과 와 일치하였고 다른 대부분의 SNP 또한 TG 또는 HDL-C 또는 GLU의 선형회귀 기울기와 MetS의 상대적 위험도가 일치하는 결과를 나타냈다. Oh 등의 연구에서 새로 발견 된 SNP인 rs964184, rs2075295, rs1558861은 TG와 연관된 결과를 보였으나, 이번 연구 결과에서는 $\mathrm{TG}$ 뿐만 아니라 HDL-C에도 연관된 결과를 나타냈다(Oh et al., 2020). BUD13 의 rs149527022는 이번 연구에서 한국인을 대상으로 대 사증후군과 연관되어 처음으로 발굴된 $\mathrm{SNP}$ 이지만 $\mathrm{TG}$ 와 $\mathrm{HDL}-\mathrm{C}$ 에는 연관성이 나타나지 않았다. 반면에 대사증후 군과 연관성을 나타내지 않았던 $Z P R I$ 의 rs145796806과 rs201247587, $A P O A 5$ 의 rs17520254는 TG와 HDL-C에서 연 관성이 나타났고 한국인을 대상으로는 처음 발굴된 SNP 이였다.
$B U C 13, Z P R 1, A P O A 5$ 유전자의 Linkage disequilibrium 구조

대사증후군과 관련된 $B U D 13, Z P R 1, A P O A 5$ 의 $\mathrm{SNP}$ 들을 대상으로 Haploview 프로그램을 통해 Linkage disequilibrium $\left(\mathrm{LD}, r^{2}\right)$ 을 확인하였다(Fig. 1). Block 1에서는 BUD13 유전자와 ZPRI 유전자 영역의 $\mathrm{SNP}$ 이 포함되어 있었고 rs149527022, rs145796806, rs201247587은 MAF (minor allele frequency)가 낮아 포함되지 않은 것으로 예측되었다. Block 2는 $A P O A 5$ 유전자의 $\mathrm{SNP}$ 이 포함되었으며 block 3은 인 근 지역의 SNP들이 LD block을 형성하였다. 대사증후군 과 높은 유의성을 나타낸 $\mathrm{SNP}$ 들이 대부분 $r^{2}$ 가 높게 나 타나 서로 연관성을 가지는 것을 알 수 있었다.

\section{Regulome DB와 GTEx Portal을 통한 in silico 기능 분석}

앞선 결과에서 유의성을 보이는 $\mathrm{SNP}$ 들이 염기에 따라 유전자 또는 단백질 발현에 영향을 주는지 알아보기 위 해 Regulome DB (https://regulomedb.org/regulome-search)와 GTEx Portal (https://gtexportal.org/home/)을 활용하여 알아보 았다(Table 4) (GTEx Consortium, 2013). Regulome DB의 결과 
Table 4. Regulome DB and GTEx Portal results of SNPs as eQTL in three genes BUD13, ZPR1 and APOA5

\begin{tabular}{|c|c|c|c|c|c|c|c|c|c|c|c|}
\hline \multirow[b]{2}{*}{ Gene } & \multirow[b]{2}{*}{ SNP } & \multirow[b]{2}{*}{ BP } & \multirow[b]{2}{*}{ A1 } & \multicolumn{6}{|c|}{ Regulome DB } & \multicolumn{2}{|c|}{ GTEx portal } \\
\hline & & & & Score & TFBS & DNase & $\begin{array}{l}\text { Proteins } \\
\text { bound }\end{array}$ & Motifs & eQTL & NES & eQTL Tissue \\
\hline \multirow{2}{*}{ BUD13 } & rs11216126 & 116617240 & $\mathrm{C}$ & 7 & - & - & - & - & - & 0.22 & Whole Blood \\
\hline & rs 2075295 & 116628401 & $\mathrm{C}$ & 6 & - & - & - & - & - & 0.14 & Whole Blood \\
\hline \multirow{2}{*}{ ZPRI } & rs964184 & 116648917 & G & $1 d$ & + & + & POLR2A & FOXJ2 & + & -0.13 & $\begin{array}{c}\text { Adipose } \\
\text { Subcutaneous }\end{array}$ \\
\hline & rs603446 & 116654435 & $\mathrm{~T}$ & $1 \mathrm{f}$ & - & + & - & - & + & - & - \\
\hline \multirow{2}{*}{$A P O A 5$} & rs 1263173 & 116681008 & A & 1f & - & + & - & - & + & - & - \\
\hline & rs7396835 & 116684028 & $\mathrm{~T}$ & 1f & - & + & $\mathrm{CDX} 2$ & - & + & - & - \\
\hline
\end{tabular}

Abbreviations: A1, minor allele; BP, base pair; eQTL, expression quantitative trait loci; NES, normalized effect size; SNP, single nucleotide polymorphism; TFBS, transcription binding factor site; +, affected; -, unaffected. Normalized effect size (NES) is defined as the slope of the linear regression, and is computed as the effect of the minor allele (A1) relative to the major allele

(A)

$$
\text { rs } 11216126
$$

BUD13 chr11_116746524_A_C_b38

Whole Blood

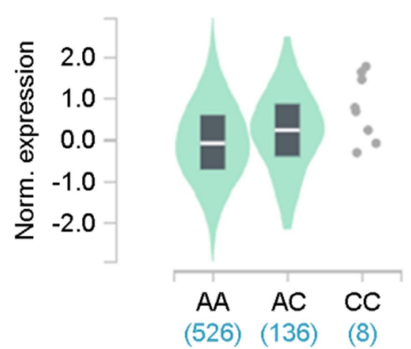

B rs2075295

BUD13 chr11_116757685_T_C_b38 Whole Blood

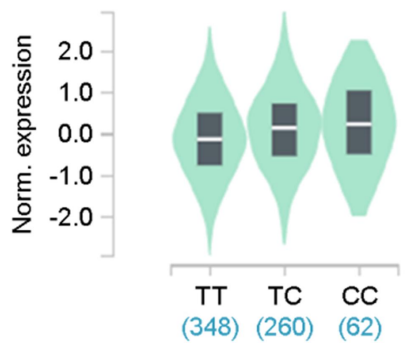

C rs964184 chr11_116778201_G_C_b38 Adipose - Subcutaneous

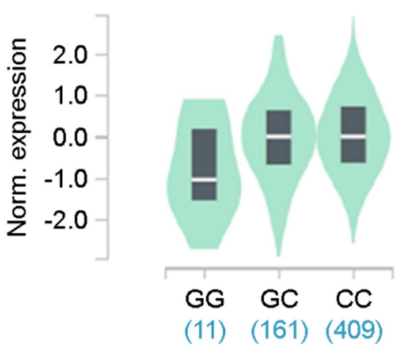

Fig. 2. Confirmation of gene expression results of SNP included in expression quantitative trait loci (eQTL) using GTEx Portal. Gene expression for each genotype in a specific tissue was confirmed and statistically significant. In (A), expression is higher when rs 11216126 of the $B U D 13$ gene has a minor allele, $\mathrm{C}$ allele, in whole blood. (B) has a higher expression in the same tissue and gene as in (A) when it has a $\mathrm{C}$ allele, a minor allele of rs2075295. In (C) Adipose-Subcutaneous, rs964184 of the ZPRI gene has low gene expression when it has a minor allele, $\mathrm{G}$ allele.

에서는 $Z P R 1$ 의 rs964184와 rs603446, $A P O A 5$ 의 rs1263173, rs7396835가 1f 이상의 score를 나타내 eQTL (expression quantitative trait loci)에 포함된 SNP임을 알 수 있었고 DNase peak의 차이를 나타냈다. 또한, rs7396835는 CDX2 단백질 결합 반응에 영향을 미쳤다. Rs964184는 1d의 score 로 전사 인자가 결합에 영향을 줄 뿐만 아니라 POLR2A 단백질 결합 반응과 FOXJ2 motif 작용에 영향을 미쳤다. GTEx Portal의 결과에서는 minor allele를 가진 경우 유전자 발현량을 Fig. 2와 같다. BUD13의 rs11216126과 rs2075295 는 전혈(whole blood)에서 minor allele를 가질 때 BUD13 유전자의 발현량이 증가하는 것을 알 수 있었고 앞서 대
사증후군 발병에 낮은 위험도를 나타낸 결과와 관련이 있 을 것으로 예상했다. Rs964184는 피하 지방(adipose subcutaneous)에서 minor allele를 가질 때 ZPR1 유전자의 발현 량이 감소하였고 마찬가지로 앞선 결과의 대사증후군 발 병의 위험 증가와 관련될 것으로 예상했다.

\section{고 찰}

염색체 11q23.3에 위치한 유전자 클러스터인 BUD13ZPR1-APOA5는 혈장 중성지방과 관상 동맥질환의 위험성 과 관련하여 잘 알려진 유전자들이다(Fu et al., 2015; Kim 
et al., 2019). BUD13 단백질은 핵 pre-mRNA retention에 영향을 미치는 splicing 인자의 서브 유닛 중 하나로 지질 대사와 관련된 명확한 메커니즘이 아직 밝혀지지 않았다 (Brooks et al., 2009). ZPR1은 세포 증식 및 신호 전달과 관련된 조절 단백질이며 ZPRI의 프로모터 부위는 peroxisome proliferator-activated receptor gamma (PPARG) 단백 질 1,2 에 결합하여 인슐린 감수성과 비만에 중요한 역할 을 가져 대사증후군과 관련될 것으로 생각된다(GalchevaGargova et al., 1996; Galcheva-Gargova et al., 1998; Corton et al., 2000). APOA5는 HDL-C의 구성 요소로써 TG를 많이 함유한 지단백질의 가수 분해(hydrolysis)와 지단백질 잔 존물(lipoprotein remnants)의 세포 내 이입을 통해 체내의 TG 농도를 조절한다(Forte et al., 2009). 따라서 각 유전자 의 유전 변이에 따라 혈중 지질 농도에 영향을 미쳐 대사 증후군 발병에 영향을 줄 것으로 예상한다. $B U D 13$ 의 rs$11216126, Z P R 1$ 의 rs603446, $A P O A 5$ 의 rs2266788, rs2075291, rs662799는 한국인을 대상으로 한 이전 연구에서 TG 또 는 HDL-C와 관련하여 밝혀진 적이 있으며 이번 연구 결 과에서도 농도 증가와 감소의 패턴이 일치하였고 유의성 이 나타났다(Melegh et al., 2012; Song et al., 2013; Gombojav et al., 2016). Oh 등의 연구에서 한국인을 대상으로 $\mathrm{TG}$ 와 관련하여 처음으로 발굴된 $Z P R 1$ 의 rs964184와 $B U D 13$ 의 rs2075295, rs1558861은 이번 연구에서 재현되어 $\mathrm{TG}$ 뿐만 아니라 대사증후군에 관련된 SNP임을 알 수 있었다 $(\mathrm{Oh}$ et al., 2020). 또한, 대사증후군에 관한 BUD13 (rs117548857, rs10488698, rs149527022, rs10790162), ZPR1 (rs2075290), $A P O A 5$ (rs12791103, $\mathrm{rs} 1263173, \mathrm{rs} 7396835)$ 과 더불어 $\mathrm{TG}$ 와 $\mathrm{HDL}-\mathrm{C}$ 에 관한 ZPR1 (rs145796806, rs201247587), APOA5 (rs17520254)가 한국인을 대상으로 한 이번 연구를 통해 새롭게 발굴되었다. 유의성을 보인 SNP들에 대하여 단백 질 발현까지의 미치는 영향과 eQTL에 해당하여 유전자 발현량의 조절 여부를 알아보았고 $\mathrm{SNP}$ 간의 LD block을 확인하였다. 따라서 HEXA 코호트 자료를 활용한 본 연 구 결과를 통해 대사증후군 발병과 혈중 지질 농도의 영 향을 미칠 수 있는 유전 인자들을 제시할 뿐만 아니라 질 환을 이해하는데 도움이 될 것으로 생각된다. 또한, 개인 의 유전적 양상을 바탕으로 발병에 차이를 나타내는 질 환의 예방과 치료에 이바지할 것으로 기대한다.

\section{ACKNOWLEDGEMENT}

This research was supported by Basic Science Research Program through the National Research Foundation of Korea
(NRF) grant (NRF-2017R1D1A3B03034752) funded by the Ministry of Education.

\section{CONFLICT OF INTEREST}

The authors have no conflicts of interest to disclose.

\section{REFERENCES}

Aguilar M, Bhuket T, Torres S, Liu B, Wong RJ. Prevalence of the metabolic syndrome in the United States, 2003-2012. JAMA. 2015. 313: 1973-1974.

Brooks MA, Dziembowski A, Quevillon-Cheruel S, Henriot V, Faux C, van Tilbeurgh H, Séraphin B. Structure of the yeast Pmll splicing factor and its integration into the RES complex. Nucleic Acids Res. 2009. 37: 129-143.

Corton JC, Anderson SP, Stauber A. Central role of peroxisome proliferator-activated receptors in the actions of peroxisome proliferators. Annu Rev Pharmacol Toxicol. 2000. 40: 491-518.

Expert Panel on Detection, Evaluation, and Treatment of High Blood Cholesterol in Adults. Executive Summary of The Third Report of The National Cholesterol Education Program (NCEP) Expert Panel on Detection, Evaluation, And Treatment of High Blood Cholesterol In Adults (Adult Treatment Panel III). JAMA. 2001. 285: 2486-2497.

Eckel RH, Grundy SM, Zimmet PZ. The metabolic syndrome. Lancet. 2005. 365: 1415-1428.

Forte TM, Shu X, Ryan RO. The ins (cell) and outs (plasma) of apolipoprotein A-V. J Lipid Res. 2009. 50 Suppl(Suppl): S150 -155 .

Fu Q, Tang X, Chen J, Su L, Zhang M, Wang L, Jing J, Zhou L. Effects of Polymorphisms in APOA4-APOA5-ZNF259BUD13 Gene Cluster on Plasma Levels of Triglycerides and Risk of Coronary Heart Disease in a Chinese Han Population. PLoS One. 2015. 10: e0138652.

GTEx Consortium. The Genotype-Tissue Expression (GTEx) project. Nat Genet. 2013. 45: 580-585.

Galcheva-Gargova Z, Gangwani L, Konstantinov KN, Mikrut M, Theroux SJ, Enoch T, Davis RJ. The cytoplasmic zinc finger protein ZPR1 accumulates in the nucleolus of proliferating cells. Mol Biol Cell. 1998. 9: 2963-2971.

Galcheva-Gargova Z, Konstantinov KN, Wu IH, Klier FG, Barrett T, Davis RJ. Binding of zinc finger protein ZPR1 to the epidermal growth factor receptor. Science. 1996. 272: 1797-1802.

Gombojav B, Lee SJ, Kho M, Song YM, Lee K, Sung J. Multiple 
susceptibility loci at chromosome 11q23.3 are associated with plasma triglyceride in East Asians. J Lipid Res. 2016. 57: 318-324.

Health Examinees Study Group. The Health Examinees (HEXA) study: rationale, study design and baseline characteristics. Asian Pac J Cancer Prev. 2015. 16: 1591-1597.

Kim HK, Anwar MA, Choi S. Association of BUD13-ZNF259APOA5-APOA1-SIK3 cluster polymorphism in 11q23.3 and structure of APOA5 with increased plasma triglyceride levels in a Korean population. Sci Rep. 2019. 9: 8296.

Kim YJ, Go MJ, Hu C, Hong CB, Kim YK, Lee JY, Hwang JY, Oh JH, Kim DJ, Kim NH, Kim S, Hong EJ, Kim JH, Min H, Kim Y, Zhang R, Jia W, Okada Y, Takahashi A, Kubo M, Tanaka T, Kamatani N, Matsuda K; MAGIC consortium, Park T, Oh B, Kimm K, Kang D, Shin C, Cho NH, Kim HL, Han BG, Lee JY, Cho YS. Large-scale genome-wide association studies in East Asians identify new genetic loci influencing metabolic traits. Nat Genet. 2011. 43: 990-995.

Kraja AT, Vaidya D, Pankow JS, Goodarzi MO, Assimes TL, Kullo IJ, Sovio U, Mathias RA, Sun YV, Franceschini N, Absher D, Li G, Zhang Q, Feitosa MF, Glazer NL, Haritunians T, Hartikainen AL, Knowles JW, North KE, Iribarren C, Kral B, Yanek L, O'Reilly PF, McCarthy MI, Jaquish C, Couper DJ, Chakravarti A, Psaty BM, Becker LC, Province MA, Boerwinkle E, Quertermous T, Palotie L, Jarvelin MR, Becker DM, Kardia SL, Rotter JI, Chen YD, Borecki IB. A bivariate genome-wide approach to metabolic syndrome: STAMPEED consortium. Diabetes. 2011. 60: 1329-1339.

Lee SE, Han K, Kang YM, Kim SO, Cho YK, Ko KS, Park JY, Lee KU, Koh EH; Taskforce Team of Diabetes Fact Sheet of the Korean Diabetes Association. Trends in the prevalence of metabolic syndrome and its components in South Korea: Findings from the Korean National Health Insurance Service Database (2009-2013). PLoS One. 2018. 13: e0194490.

Lee SH, Tao S, Kim HS. The Prevalence of Metabolic Syndrome and Its Related Risk Complications among Koreans. Nutrients. 2019. 11:1755.

Melegh BI, Duga B, Sümegi K, Kisfali P, Maász A, Komlósi K,
Hadzsiev K, Komoly S, Kosztolányi G, Melegh B. Mutations of the apolipoprotein A5 gene with inherited hypertriglyceridaemia: review of the current literature. Curr Med Chem. 2012. 19: 6163-6170

Mottillo S, Filion KB, Genest J, Joseph L, Pilote L, Poirier P, Rinfret S, Schiffrin EL, Eisenberg MJ. The metabolic syndrome and cardiovascular risk a systematic review and meta-analysis. J Am Coll Cardiol. 2010. 56: 1113-1132.

Moon S, Kim YJ, Han S, Hwang MY, Shin DM, Park MY, Lu Y, Yoon K, Jang HM, Kim YK, Park TJ, Song DS, Park JK, Lee JE, Kim BJ. The Korea Biobank Array: Design and Identification of Coding Variants Associated with Blood Biochemical Traits. Sci Rep. 2019. 9: 1382.

Oh C, Kim HS. Metabolic syndrome and its related factors among Korean elderly in urban and rural Areas. Culinary science and hospitality research. 2016. 1: 32-41.

Oh SW, Lee JE, Shin E, Kwon H, Choe EK, Choi SY, Rhee H, Choi SH. Genome-wide association study of metabolic syndrome in Korean populations. PLoS One. 2020. 15: e0227357.

Song KH, Cha S, Yu SG, Yu H, Oh SA, Kang NS. Association of apolipoprotein A5 gene -1131T $>$ C polymorphism with the risk of metabolic syndrome in Korean subjects. Biomed Res Int. 2013. 2013: 585134.

Sung J, Lee K, Song YM. Heritabilities of the metabolic syndrome phenotypes and related factors in Korean twins. J Clin Endocrinol Metab. 2009. 94: 4946-4952.

Wang Y, Mi J, Shan XY, Wang QJ, Ge KY. Is China facing an obesity epidemic and the consequences? The trends in obesity and chronic disease in China. Int J Obes (Lond). 2007. 31: 177-188.

https://doi.org/10.15616/BSL.2020.26.4.368

Cite this article as: Kim SS, Park S, Jin HS. Replicated Association Study for Metabolic Syndrome of the Gene Cluster in Chromosome 11q23.3. Biomedical Science Letters. 2020. 26: 368-375. 